Gazi University
Journal of Science
$\mathrm{http} / /$ dergipark.gov.tr/gujs

\title{
Decision Making in Evaluation and Selection of Launch Site with The Best and Worst Method
}

\author{
Ibrahim $\mathrm{OZ}^{*}$ \\ Türksat Uydu Haberleşme ve Kablo TV AŞ, Cevizlidere Cad. No:31, Ankara, Turkey
}

Article Info

Received: 17 Apr 2020 Accepted: 24 Nov 2021

\section{Keywords}

Launch site

Spacecraft launch

Satellite launch

Decision making

Best and worst method

\begin{abstract}
Launch site location selection is a critical managerial and technical decision-making problem in the space industry. The criteria obtained from a massive amount of essential factors, considerations, and pre-requests provide input for the assessment process. The decision-makers evaluate many candidate launch site locations considering various aspects during the evaluation phase. The best worst method developed recently is a multi-criteria decision-making process proposed to evaluate the criteria' weights in this work. The weights of technical, commercial, and safety, which are primary criteria, and twelve sub-criteria are evaluated with the proposed method. The weights of the criteria and the importance of technical, managerial focusing factors are determined with the BWM. The results assist the administrators in selecting the best priority launch site. The best worst method provides reliable and usable results that are also consistent with the other evaluation. The uncertainties associated with the input parameters have been analyzed with the Ben-Tal best and worst methods. In a launch site for Turkey's illustrative example, Sinop is selected as the best priority launch site in Turkey's provinces, and Somalia is found the best-proposed launch site location among four candidates. Appropriately established launch site supports accessing space successfully.
\end{abstract}

\section{INTRODUCTION}

A launch site is a complex that is capable of launching launch vehicles with payloads to desired orbits. Payload spacecraft processing unit, vehicle assembly and integration area, storage facilities for fuel and gases, access road, flight tracking and commanding stations, and expandable elements are central parts of a launch site. All infrastructures of a site support launches and launch vehicles to reach the desired orbit successfully. A launch site is an essential part of high tech space technologies. Countries would like to develop this challenging space technology and have the ability to access space. In this study, commercial and governmental launch site location developments are evaluated. Assuming the rockets from this site launch satellites, space flight participants, scientific experiments, and other payloads to earth orbits. Earth orbits cover geosynchronous orbit, low earth orbit, polar orbit, medium earth orbit, elliptical orbit, or highly elliptical orbits in this work. However, lunar missions and interplanetary missions are excluded because they require modifying criteria due to escaping earth orbit properties. A launch site for commercial and governmental space missions is developed based on the objectives, criteria, and method. The administrators propose the objectives. Based on the proposal's requirement, the relevant criteria determination and evaluation methods are developed to support the administrators. Before deciding to build a launch site, several candidate locations sites must be selected and compared rigorously based on criteria and method. The evaluation results are presenting optimal alternatives for decision-making. The solution to site selection can be unique or multi-optimal. 


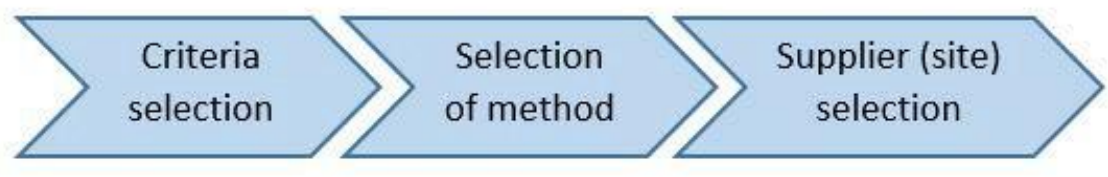

Figure 1. Basic stages of a site selection process

Generally, a site selection process involves three primary stages, as shown in Figure 1. The first stage is the determination of criteria. The second stage is the determination of methods for the assessment of sites based on criteria. The third (last) stage is the selection of sites (suppliers) based on the assessment results [1]. The first stage in the field of criteria determination explains how decision criteria are selected. The second stage proposes a method for assessment. The third stage is the application level selecting a site with the proposed method in this work.

Many criteria in a different kind of site selection have been developed in the literature. Methods and criteria developed for practical implementation, especially have a high correlation with spaceport location selection, were reviewed. It has been recognized that the decision methods have advantages and disadvantages based on the design of criteria [1]. The selected criteria and methods affect the results in all decision making. Indonesian rocket technology center evaluates spaceport site selection with analytic hierarchy process decision making. Economic, environmental, technical, safety, and meteorological factors are key criteria in spaceport selection [2]. A site selection of potential observatory locations in Turkey investigation shows that due to the nature of the problem, there are multiple criteria that affect decisionmaking [3]. For the United States case, the Federal Government executed launch site development for many years. It is recognized that the evolution of these launch site development model depends on the technical, cost, safety, schedule, and political requirements of launch vehicle programs. The private launch companies have different requirements than the government-supported launch operators in terms of launch site technical capabilities, costs, safety, and schedules [4]. In terms of operational satisfaction and in terms of expenses, site selection is a strategic decision. The site selection decision is a long-term investment. Longterm investment decisions are difficult and costly to change [5]. Many sophisticated and inter-related processes and parameters are taken into consideration to determine the appropriate location from among the possibilities. Location selections are an extremely complex and vital process [6]. Astronomical observatory site selection is another correlated work area of launch site selection. It is a complex problem like launch site selection that involves the evaluation of multiple factors from different sources. Multicriteria decision analysis with geographical information systems and remote sensing technologies can be utilized to select the best possible candidates' sites [7]. Space launch system cost factors must be well understood to analyze a potential business case and its development. Selection, design construction, and starting operation of a launch complex represents a high non-recurring cost. Launch site cost-driven factors must be analyzed deeply, and possible cost reduction decisions should be taken to have the best possibility of economic success. Launch vehicle and site location play a major role in establishing costs [8]. In site selection and other fields, academic experts and practitioners have some idea about the level of forcing factors. The Best Worst Method (BWM) can be utilized to identify the collective importance of the forces. The method could help a company determine how changes in the importance of each external force could influence decision-making processes, thus the resulting strategy [9].

It has been noted that all works in site selection aim to reduce costs and maximize services for the various countries for various interests.

The second stage is the determination of methods. Multi-criteria decision-making (MCDM) problems are generally comprised of five components, which are; goal, decision-makers, preferences, alternatives, criteria, and outcomes. Different methods or models can approach a particular problem that has its drawbacks and restrictions [10]. Table 1 is extracted from Abhishek Kumara et al. paper title as "A review of multi-criteria decision making (MCDM) towards sustainable renewable energy development". It shows a simplified summary of popular decision analysis methods and their area of application and strength and weakness [10]. 
Table 1. Multi Criteria Decision Making methods, strength and weakness

\begin{tabular}{|l|l|l|}
\hline Methods & Strength & Weakness \\
Method & $\begin{array}{l}\text { 1. Simple computation. } \\
\text { 2. Suitable for single dimension problem }\end{array}$ & $\begin{array}{l}\text { 1. Only a basic estimate 2. Fails to } \\
\text { integrate multiple preferences }\end{array}$ \\
\hline $\begin{array}{l}\text { Analytical hierarchy } \\
\text { process (AHP) }\end{array}$ & $\begin{array}{l}\text { 1.Adaptable 2. Does not involve } \\
\text { complex mathematics 3. Each criteria } \\
\text { can be better focused and transparent }\end{array}$ & $\begin{array}{l}\text { 1. Inter dependency 2. Involvement } \\
\text { of more decision maker 3. Demands } \\
\text { data collected based on experience }\end{array}$ \\
\hline $\begin{array}{l}\text { Elimination and } \\
\text { Choice Translating } \\
\text { Reality (ELECTRE) }\end{array}$ & $\begin{array}{l}\text { 1. Deals with both quantitative and } \\
\text { qualitative features of criteria. 2. Final } \\
\text { results are validated with reasons }\end{array}$ & $\begin{array}{l}\text { 1. Less versatile 2. Demands good } \\
\text { understanding of objective specially } \\
\text { when dealing with quantitative features. }\end{array}$ \\
$\begin{array}{l}\text { Technique for Order } \\
\text { Preference by } \\
\text { Similarity (TOPSIS) }\end{array}$ & $\begin{array}{l}\text { 1. Works with fundamental ranking 2. } \\
\text { information. }\end{array}$ & $\begin{array}{l}\text { 1.Works on the basis of Euclidean } \\
\text { distance. 2.The attribute values } \\
\text { should be monotonically increasing } \\
\text { or decreasing. }\end{array}$ \\
\hline $\begin{array}{l}\text { Vise Kriterijumska } \\
\text { Opt.I Kompromisno } \\
\text { Resenje (VIKOR) }\end{array}$ & $\begin{array}{l}\text { 1. An updated version of TOPSIS 2. } \\
\text { Calculates ration of positive and } \\
\text { negative ideal solution. }\end{array}$ & $\begin{array}{l}\text { 1. Difficulty when conflicting } \\
\text { situation arises. 2. Need modification } \\
\text { while dealing with some data. }\end{array}$ \\
\hline $\begin{array}{l}\text { Preference Ranking } \\
\text { Structural analysis } \\
\text { (PROMETHE) }\end{array}$ & $\begin{array}{l}\text { 1. Involves group level decision 2. } \\
\text { Deals with qualitative and quantitative } \\
\text { information 3. Incorporate uncertain } \\
\text { info. }\end{array}$ & $\begin{array}{l}\text { 1. Does not structure the objective } \\
\text { properly 2. Depends on the decision } \\
\text { maker to assign weight } \\
\text { 3. Complicated }\end{array}$ \\
\hline $\begin{array}{l}\text { Multi attribute utility } \\
\text { theory (MAUT) }\end{array}$ & $\begin{array}{l}\text { 1. Simultaneously compute preference } \\
\text { order for all alternatives } \\
\text { 2. Dynamically updates value changes. }\end{array}$ & $\begin{array}{l}\text { 1. Difficult to have precise input } \\
\text { from decision maker. 2. Outcome of } \\
\text { the decision criteria is uncertain }\end{array}$ \\
\hline
\end{tabular}

Evaluation of the weights of the criteria and site selection is an MCDM problem. MCDM is an evaluation structure to solve technical, economic, safety, and environmental problems for supplier allocation. Systematic reviews on articles on the application of MCDM show that based on the principle behind these MCDM techniques, we can classify them into four categories [11].

1. Multi-attribute utility methods; AHP and ANP

2. Outranking method; ELECTRE and PROMETHEE

3. Comparison methods; TOPSIS and VIKOR

4. Other MCDM method; SMART and DEMATEL

This study investigates a launch site for commercial and governmental space missions based on the objectives, criteria, and method. Findings are presenting optimal alternatives for decision-making.

\section{SELECTON OF CRITERIA AND EVALUATION METHOD}

Turkey would like to consolidate and expand space activities. Turkish space agency established to build space capacity and manage the activities. One of the critical subjects in space technology is to access space with national abilities. The institution's engineers worked on launch site selection to support the administrators at the ministry level. The decision-makers evaluated launch site candidates using the weighted sum model based on the experts selected and graded criteria.

After reviewing many MCDM techniques, we proposed newly developed the best and the worst method to evaluate the weights of the criteria for site selection because the best worst method requires less information than other methods while evaluating criteria and provides more consistency [12]. 


\subsection{Review and Selection of Criteria}

The determination of criteria is the first important step in multiple criteria evaluation problems. The finite number of criteria must be explicitly known at the beginning of the process. In this study, the decisionmakers determined site selection criteria based on land use and accessibility, existing infrastructure, topography and soil characteristics, orbital insertion physics, air traffics, socioeconomic, meteorological conditions, general environmental considerations, and other essential factors. From a massive amount of criteria, the most significant criteria are grouped, refined, and clarified from many candidate criteria to represent several considerations and pre-requests. Finally, three primary criteria and twelve sub-criteria are determined for assessment. Technical operations, commercial (economical), and safety (security) criteria are part of the primary criteria. Each primary criteria were subdivided into four sub-criteria, as shown in Table 2.

Table 2. Launch site selection primary criteria and their sub-criteria

\begin{tabular}{|c|c|c|c|}
\hline & Primary criteria & & Sub-criteria \\
\hline \multirow{5}{*}{1} & \multirow{4}{*}{ Technical } & 1.1 & Launch vehicle (LV) \\
\hline & & 1.2 & Orbit type (OT) \\
\hline & & 1.3 & Distance to equator (DE) \\
\hline & & 1.4 & Launchpad properties (LP) \\
\hline & \multirow{4}{*}{ Commercial } & 2.1 & Infrastructure (IS) \\
\hline \multirow{4}{*}{2} & & 2.2 & Transportation (TP) \\
\hline & & 2.3 & Marketing (MK) \\
\hline & & 2.4 & Launch environment (LE) \\
\hline & \multirow{4}{*}{ Safety } & 3.1 & Flight trajectory (FT) \\
\hline \multirow{3}{*}{3} & & 3.2 & Population density (PD) \\
\hline & & 3.3 & Weather conditions (WC) \\
\hline & & 3.4 & Potential disaster (PS) \\
\hline
\end{tabular}

Technical operations criteria cover launch vehicles, payload, and ground system operations. It is summarized in four sub-criteria. Those sub-criteria are defined below. 1.1 The launch vehicles (LV) and their performance. Assuming LV has two or three stages and it is a single-use expendable rocket having the ability to inject payload into desired orbits.1.2 orbit types (OT), it identifies different earth orbits, such as low orbit, polar orbit, medium orbit, elliptical orbit, geo transfer orbit, geosynchronous orbit, and orbital insertion physics. 1.3 distance to the equator (DE), size of the gap from site location to earth latitude of 0 degrees, mainly affects communication satellite orbital injection performance, and lower latitude is better than higher latitude. 1.4 launchpads properties (LP) refers to support launch vehicles for different types of missions and relevant orbits together with payload processing and final check building.

Commercial (economic) criteria discuss cost rationale for site selection such as initial capital, ongoing operations cost, energy and water supply, airport, ports, access roads, etc. It is subdivided into four subcriteria. 2.1 infrastructure (IS) is fundamental facilities and systems serving for a launch site, including but not limited to payload processing units, ground systems, clean rooms. Cost factors of infrastructure are taken into account. 2.2 transportations (TP) refer to the payload (spacecraft/satellite), launch vehicle and fuel transportation, and other transport items. 2.3 marketing (MK) is the effect of geographical location on to market and sale of the launch mission. 2.4 launch environment (LE) is a commercial assessment of a launch site.

Safety (security) criteria consist of security and risk assessments, landing, off-site landing, path safety, interference, contamination from potential releases of a launch vehicle, noise pollution to populated areas, sufficient distance to equipment, etc. Safety criteria have four sub-criteria. Those are 3.1 flight trajectory (FT) is the flight path that a launch vehicle and its payload flow through space considering safe jettisoning and emergency mission abort. 3.2-population density (PD) is the number of people around the flight path. A rural area must be selected for safety reasons if possible. 3.3 weather conditions (WC) is an important 
parameter that affects launch time in the launch window. Such as a launch vehicle go or no-go status due to higher altitude wind speed, rain, and some other meteorological conditions. 3.4 potential disaster (PS) is a possibility of a disaster such as lightning, earthquake, flood, etc. around the site.

\subsection{Determination of Candidate Site Locations and Data Sets}

The third stage of the process is the selection of candidate sites. Turkey is roughly geographically between $26^{0}-45^{0}$ East longitude and $36^{0}-42^{0}$ North latitude. The decision-makers identify candidate locations based on several assessment criteria and pre-requests. As an illustrative example, candidate launch locations are determined and examined. Four locations are selected for investigations for Turkey as shown in Figure 2. North, south, or west locations are examined as a potential area to build a launch site to cover all geography. East candidate locations are disregarded due to a lack of technical and safety considerations. Sinop, Kumluca, Korucam, and Somalia are carried forward for further assessment.

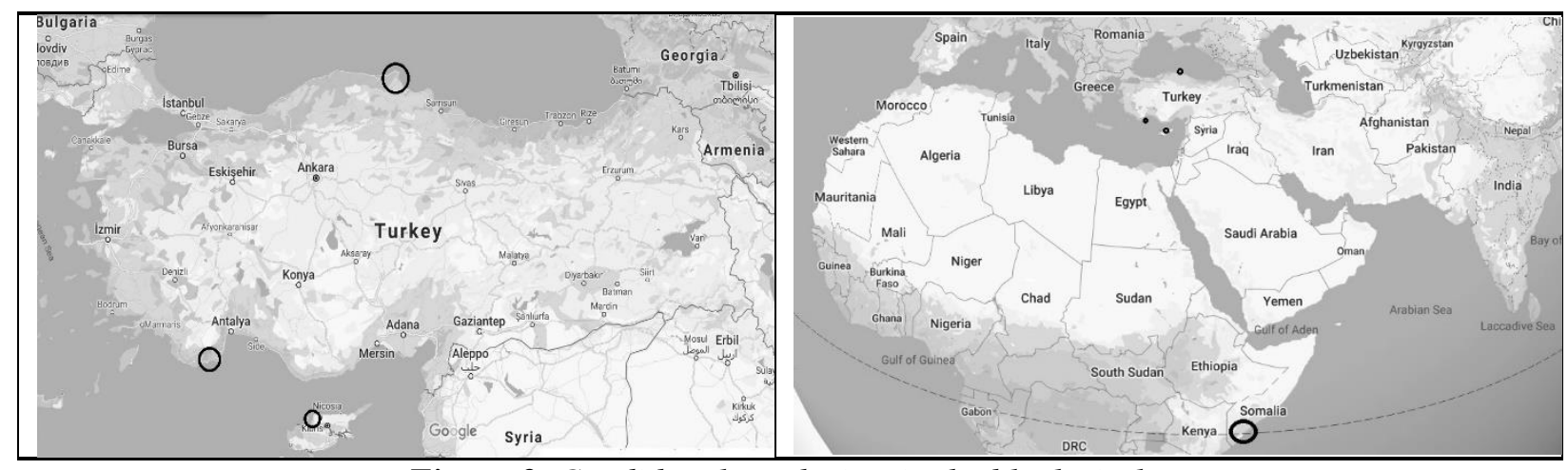

Figure 2. Candidate launch sites in the black circles

The primary approach in considering Sinop $\left(42.28^{0} \mathrm{~N}, 35.18^{0} \mathrm{E}\right)$ place is Turkey's northernmost province. The second select Antalya / Kumluca $\left(36.25^{0} \mathrm{~N}, 30.42^{0} \mathrm{E}\right)$ is one of Turkey's southernmost cities. For better flight safety, a site outside of Turkey but at the same time close to Turkey Cyprus Korucam $\left(35.35^{0} \mathrm{~N}\right.$, $\left.32.96^{0} \mathrm{E}\right)$ is selected. Although it is a foreign country, Somalia $\left(0.05^{0} \mathrm{~N}, 42.85^{0} \mathrm{E}\right)$ is chosen as one of the potential places to recognize the advantages of being on the equator and better safety for the flight paths. Launch site's latitude and longitude values do not show exact locations but show candidate locations around there.

The decision-makers assess site scores (data set) for sub-criteria based on experiences and available data. Those sub-criteria scores are input values for three types of methods shown in this work. The final results for ranking are calculated using these scores in Table 3 and computed criteria weights.

Table 3. The scores of sub-criteria for $\left(a_{i j}\right)$ different site locations provided by the experts

\begin{tabular}{l|llll|llll|llll}
\hline Location & LV & OT & LP & DE & IS & TP & LE & MK & FT & PD & WC & PS \\
\hline Sinop & 100 & 50 & 100 & 30 & 90 & 85 & 80 & 70 & 70 & 80 & 80 & 90 \\
Kumluca & 100 & 60 & 100 & 45 & 90 & 85 & 70 & 75 & 60 & 60 & 80 & 80 \\
Korucam & 100 & 70 & 100 & 60 & 80 & 85 & 75 & 80 & 75 & 75 & 85 & 80 \\
Somalia & 100 & 95 & 100 & 100 & 60 & 60 & 95 & 60 & 100 & 100 & 85 & 70 \\
\hline
\end{tabular}

\subsection{The Best and the Worst Method}

The best worst method is a multi-criteria decision-making method. Rezaei recently proposed the best worst method linear model to determine the final weights of various criteria [12]. It uses two vectors of pairwise comparison to determine the weights of criteria. This method lowers the inconsistency of the results. It reduces the number of comparisons relative to other methods. Several researchers have applied the best worst method to address different problems. The BWM has been widely utilized in numerous real-world problems, such as supply chain management, energy, transportation, investment, banking, manufacturing, 
education, site selection, performance evaluation, communication and technology [13,14]. The pairwise comparisons of criteria have a long tradition in multi-criteria decision-making since the introduction of the Analytic Hierarchy Process (AHP) in 1980. One of the main drawbacks of the AHP refers to the inconsistency of decision-makers in pairwise comparisons. The Best-Worst Method (BWM) was introduced to reduce the inconsistency by a concept that needs substantially less pairwise comparisons [15]. The linear best worst method was applied to this work to determine the criteria weights. In this method, we track the following steps to calculate the weights of the criteria;

1. Define a set of criteria (already performed in stage 1),

2. Define the best and the worst criteria,

3. Define the preferences of the best over the other (determination of pairwise comparison matrix),

4. Define the preferences of all criteria over the worst (determination of pairwise comparison matrix),

5. Search for the optimal solution (finding the best solution).

The decision makers (the experts) performed the first four steps. Initially, the decision-makers identify $n$ criteria.

$$
c_{1}, c_{2}, c_{3}, \ldots \ldots c_{n}
$$

Secondly, the best (most desirable, most important) and the worst (least desirable, least important) criteria are determined. Then the preference of the best criterion over the other criteria, using a number between 1 and 9 are determined. The resulting best-to-others (BO) vector is;

$$
A_{B}=\left(a_{B 1}, a_{B 2}, a_{B 3}, \ldots, a_{B n}\right)
$$

where $a_{B j}$ indicates the preference of the best criterion B over criterion $j$. It is clear that $a_{B B}=1$.

The preference of the criteria over the worst criterion, using a number between 1 and 9 are determined. The meaning of the numbers $1-9$ are

1: Equal importance, 2: Somewhat between equal and moderate, 3: Moderately more important, 4: Somewhat between moderate and strong, 5: Strongly more important, 6: Somewhat between strong and very strong, 7: Very strongly important, 8: Somewhat between very strong and absolute, 9: Absolutely more important.

The resulting others-to-worst (OW) vector is

$$
A_{w}=\left(a_{1 w}, a_{2 w}, a_{3 w}, \ldots, a_{n w}\right)^{T}
$$

where $a_{j w}$ indicates the preference of the criterion $j$ over the worst criterion $w$. It is clear that $a_{w w}=1$. Optimal weights $\left(w_{1}{ }^{*}, w_{2}{ }^{*}, w_{3}^{*}, \ldots ., w_{n}^{*}\right)$ and the maximum absolute differences are

$$
\left|\frac{w_{B}}{w_{i}}-a_{B J}\right| \leq \xi^{L} \quad \text { and } \quad\left|\frac{w_{j}}{w_{w}}-a_{j w}\right| \leq \xi^{L}
$$

For all $j$ is minimized, which is translated to the following min max model

$$
\max _{j}=\left\{\left|\frac{w_{B}}{w_{j}}-a_{B J}\right|,\left|\frac{w_{j}}{w_{w}}-a_{j w}\right|\right\}
$$




$$
\sum_{j}^{s, t} w_{j}=1
$$

$w_{j} \geq 0$, for all $j, \xi^{L}$ is an indicator of consistency of the comparison.

Optimal weights of criteria $\mathrm{w}_{\mathrm{n}}$ are calculated by solving the matrix based on selected criteria $\mathrm{c}_{\mathrm{n}} . \xi^{L^{*}}$ shows the lowest value. The lower value represents the higher consistency.

\subsection{Evaluation of Launch Sites}

The application of the best and the worst method mentioned above for launch site criteria are as follow; The decision-makers consider three primary criteria, technical $\left(\mathrm{c}_{1}\right)$, commercial $\left(\mathrm{c}_{2}\right)$, and safety (c3), to evaluate the weights of the criteria. The best (most desirable, the most important) and the worst (the least desirable, the least important) criteria are determined. The best criterion and the preference over the worst are expressed by selecting a number between 1 to 9 . As shown in Table 4, the pairwise comparison vector is obtained to evaluate the weights of three primary criteria.

Table 4. Best-to-others $(\mathrm{BO})$ and others-to-worst $(\mathrm{OW})$ pairwise comparison vectors of primary criteria

\begin{tabular}{llll}
\hline BO & Technical & Commercial & Safety \\
Best Criteria: Technical & 1 & 3 & 2 \\
\hline OW & Worst Criteria: Commercial & \\
Technical & & 3 & \\
Commercial & & 1 & \\
Safety & & 2 & \\
\hline
\end{tabular}

Similarly, the same procedure is applied to assess the sub-criteria. The pairwise comparison vectors are obtained, as shown in Table 5 for sub-criteria of primary criteria by selecting the best and the worst and expressing the preferences over the others as mentioned above.

Table 5. Best-to-others $(\mathrm{BO})$ and others-to-worst $(\mathrm{OW})$ pairwise comparison vectors of sub-criteria. Best criteria $(B C)$ vs worst criteria $(W C)$

\begin{tabular}{|c|c|c|c|c|c|c|c|c|c|c|c|c|c|c|}
\hline$\overline{\mathrm{BO}}$ & LV & OT & $\mathrm{DE}$ & LP & $\mathrm{BO}$ & IS & TP & MK & LE & BO & FT & PD & WC & PS \\
\hline$B C: L V$ & 1 & 2 & 2 & 5 & BC:IS & 1 & 2 & 6 & 3 & BC:FT & 1 & 2 & 8 & 2 \\
\hline$\overline{\mathrm{OW}}$ & & WC: & LP & & OW & & WC & MK & & OW & & WC & WC & \\
\hline LV & & & 6 & & IS & & & 5 & & PD & & & 8 & \\
\hline OT & & & 4 & & $\mathrm{TP}$ & & & 4 & & FT & & & 3 & \\
\hline $\mathrm{DE}$ & & & 3 & & MK & & & 1 & & WC & & & 1 & \\
\hline LP & & & 1 & & LE & & & 3 & & PS & & & 4 & \\
\hline
\end{tabular}

The above pairwise comparison vector shown in Tables 4 and 5 are input of the BWM.

\subsection{Applying Uncertainties to the BWM, Ben-Tal Method}

The decision-maker's data have inherent biases in subjective judgment. To overcome errors related to fixed input can be eliminated using an interval. The drawback of the BWM is its fixed input values [16]. We must add uncertainties (errors) to the problem for rational decision-making. The uncertainties associated with the input parameter are one of the primary concerns in most decision-making problems. The decisionmakers sometimes cannot assign an exact value to each input parameter and may assign an interval of values to input parameters. The linear best worst method with errors was applied to analyze the effect of the uncertainties. Sayed J.S. et al. studied three different robust formulation for the BWM with uncertainties 
and concluded that Ben-Tal and Nemirovski method provides successful results. The Ben-Tal and Nemirovski non-linear model robust formulations for BWM is implemented as a linear equation by Sayed J. S. et al. [16]. The derivation of the model from the original Ben-Tal approach can be found in the Sayed J.S. et al. study. The final derived formulation is shown in Equation (7)

$$
\sum_{j}^{n} w_{j}=1
$$

$w, y \geq 0, \mathrm{z}$ and $\mathrm{y}$ robustness values added.

To analyze errors in launch site criteria, we use the Ben-Tal method to solve uncertain vectors. We applied $\pm 20 \%$ uncertainty (error) to pairwise comparison matrices to evaluate the effect of uncertainties or reviewer bias on this study's results. According to the historical data, we assume the decision-makers have $80 \%$ trust, so the $\pm 20 \%$ uncertainty (error) was selected, but different uncertainty values can be assigned to observe the variations. The pairwise new comparison vector with uncertainties is obtained to evaluate the primary criteria set's weights, as shown in Table 6.

Table 6. Best-to-others $(B O)$ and others-to-worst $(O W)$ pairwise comparison vectors of primary criteria with uncertainties

\begin{tabular}{llll}
\hline BO & Technical & Commercial & Safety \\
Best Criteria: Technical & $1 \pm 0.2$ & $3 \pm 0.6$ & $2 \pm 0.4$ \\
\hline OW & Worst Criteria: Commercial & \\
Technical & & $3 \pm 0.6$ & \\
Commercial & & $1 \pm 0.2$ & \\
Safety & & $2 \pm 0.4$ & \\
\hline
\end{tabular}

Similarly, we applied a 20\% error to input values of sub-criteria, and then the pairwise comparison vectors with errors are obtained, as shown in Table 7 for each sub-criteria set. The solution of the new pairwise comparison vectors results in sub-criteria weights, including uncertainties.

Table 7. Best-to-others $(\mathrm{BO})$ and others-to-worst $(\mathrm{OW})$ pairwise comparison vectors of sub-criteria with uncertainties. Best criteria $(B C)$ vs worst criteria $(W C)$

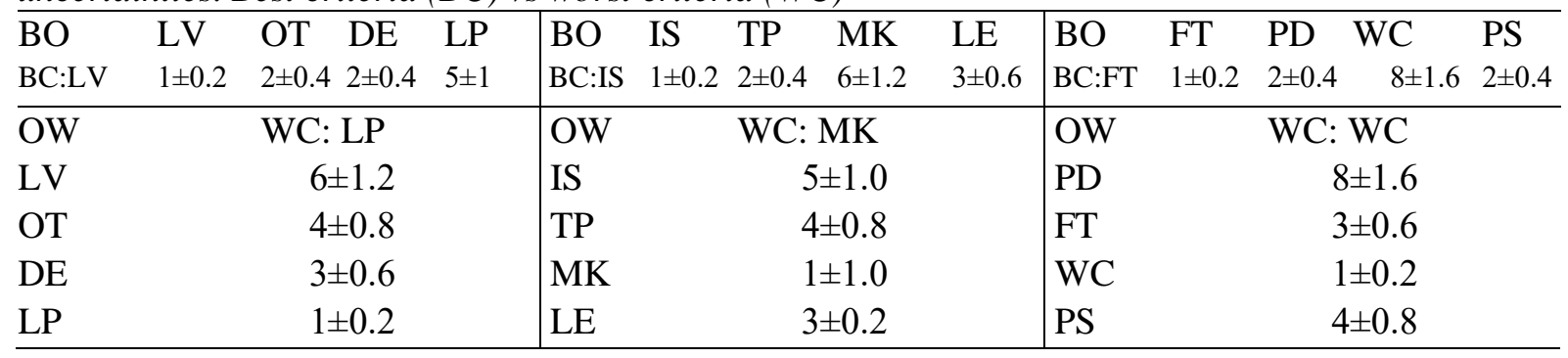

We use Ben-Tal, the best and worst method, to find an optimal solution to the uncertainty applied above matrices because this method allows a range of data in the input instead of a fixed value. This model is linear, and any typical solver can solve it. In this study, the MATLAB codes were utilized to solve the matrices and obtain the results.

\subsection{The Expert Evaluation Method}

The reviewers (engineers) have experience in space activities and operations subject and project evaluations. The experts assess the subject by using unpublished knowledge and wisdom in experts' heads, based on their accumulated experience and expertise. The experts provide an evaluation by a systematic approach and synthesized subjective judgments. In this work, the criteria and the pairwise comparison matrices are given above are selected and assessed by the experts. 


\subsection{Weighted Sum Method (WSM)}

The final evaluation scores of the candidate sites were calculated by using the weighted sum model. The final score of the launch site for three methods, The BWM, the Ben-Tal method, and the expert evaluation, are calculated by using the following Equation (8)

$$
A_{i}^{W S M-s c o r e}=\sum_{j=1}^{n} w_{j} a_{i j}
$$

where $w_{j}$ : weights of criteria, $a_{i j}$ : performance value of alternative, $A_{i}$ : computed value of alternatives. $w_{j}$ determines the selected method for computation, the bwm, the experts (intuitive) or with errors method.

\section{RESULTS AND DISCUSSION}

The weights of the criteria are obtained in three different methods. First, the weights of the primary criteria are evaluated by solving the pairwise comparison vector-matrix, as shown in Table 4, using the linear best and the worst method. The results indicate that technical criteria weight is $\mathrm{w}_{1}=54.16 \%$, commercial criteria weight is $\mathrm{w}_{2}=16.67 \%$, safety criteria weight is $\mathrm{w}_{3}=29.17 \%$ and $\xi^{\mathrm{L}^{*}}=0.0416$ as shown in Table 8 . The consistency value of primary criteria is 0.0416 ; consequently, the comparison system is consistent and provides reliable results. The weight of the most important criteria is close to $50.00 \%$.

The evaluation outcome shows that technical criteria are the most critical criteria throughout the site selection process. Operational safety analysis has secondary importance. Commercial and economics have the third priority among primary criteria. Regarding four sub-criteria of each primary criteria, the weights of infrastructure, population density, and launch vehicle have the most importance in their group. The values of weights are $47.15 \%, 46.88 \%$, and $43.40 \%$, respectively. Consistency values $\xi^{L^{*}}$ for sub-criteria are $0.0566,0.0650$, and 0.0313 , as shown in the last column of Table 8 . Those values are close to 0 and show a consistent solution of the matrix. Consequently, it is expected to achieve reliable results.

Table 8. The Weights of the criteria and their consistency values evaluated with the proposed BWM (BO) and others-to-worst $(\mathrm{OW})$ pairwise comparison vectors of sub-criteria

\begin{tabular}{|c|c|c|c|c|c|c|}
\hline $\begin{array}{l}\text { Primary } \\
\text { Criteria }\left(c_{n}\right)\end{array}$ & $\begin{array}{l}\text { Weights } \\
\left(w_{n}\right)\end{array}$ & $\xi^{L^{*}}$ & Sub-criteria $\left(c_{n}\right)$ & $\begin{array}{l}\text { Local } \\
\text { Weights }\left(w_{n}\right.\end{array}$ & $\begin{array}{l}\text { Global } \\
\text { Weights }\end{array}$ & $\xi^{L^{*}}$ \\
\hline \multirow{4}{*}{ Technical } & \multirow{4}{*}{0.5417} & \multirow{12}{*}{0.0416} & Launch Vehicle & 0.4340 & 0.2350 & \multirow{4}{*}{0.0566} \\
\hline & & & Orbit type & 0.2453 & 0.1328 & \\
\hline & & & Distance to Equator & 0.2453 & 0.1328 & \\
\hline & & & Launchpad & 0.0755 & 0.0408 & \\
\hline \multirow{4}{*}{ Commercial } & \multirow{4}{*}{0.1667} & & Infrastructure & 0.4715 & 0.0785 & \multirow{4}{*}{0.0650} \\
\hline & & & Transportation & 0.2683 & 0.0447 & \\
\hline & & & Marketing & 0.0813 & 0.0135 & \\
\hline & & & Launch Environment & 0.1789 & 0.02982 & \\
\hline \multirow{4}{*}{ Safety } & \multirow{4}{*}{0.2917} & & Population Density & 0.2188 & 0.0064 & \multirow{4}{*}{0.0650} \\
\hline & & & Flight Trajectory & 0.4688 & 0.1367 & \\
\hline & & & Weather condition & 0.0625 & 0.0182 & \\
\hline & & & Potential Disaster & 0.2500 & 0.0729 & \\
\hline
\end{tabular}

The weights of the criteria and the importance of technical, managerial focusing factors are determined with the method. 
Secondly, the weights of the primary criteria set and sub-criteria sets are including input uncertainties, are computed with the Ben-Tal method, as shown in Table 9. The results are very similar to fixed input values. There is no change in the rank of the criteria. However, the consistency value for the primary criteria set and sub-criteria sets are higher than the fixed input values solution shown in Table 8. Increasing the consistency value means the results are less reliable compared to a fixed input.

Table 9. The weights of the criteria evaluated with applying 20\% uncertainty (error) and Ben-Tal BWM

\begin{tabular}{|c|c|c|c|c|c|c|c|}
\hline $\begin{array}{l}\text { Primary } \\
\text { criteria }\left(c_{n}\right)\end{array}$ & Error & $\begin{array}{l}\text { Weights } \\
\left(w_{n}\right)\end{array}$ & $\xi^{L^{*}}$ & Sub- criteria $\left(c_{n}\right)$ & Error & $\begin{array}{l}\text { Weights } \\
\left(w_{n}\right)\end{array}$ & $\xi^{L^{*}}$ \\
\hline \multirow{4}{*}{ Technical } & \multirow{4}{*}{ $\pm 20 \%$} & \multirow{4}{*}{0.5454} & \multirow{12}{*}{0.1317} & Launch Vehicle & \multirow{4}{*}{ $\pm 20 \%$} & 0.4414 & \multirow{4}{*}{0.1379} \\
\hline & & & & Orbit type & & 0.2414 & \\
\hline & & & & Distance to Equator & & 0.2414 & \\
\hline & & & & Launchpad & & 0.0759 & \\
\hline \multirow{4}{*}{ Commercial } & \multirow{4}{*}{ $\pm 20 \%$} & \multirow{4}{*}{0.1724} & & Infrastructure & \multirow{4}{*}{ $\pm 20 \%$} & 0.4813 & \multirow{4}{*}{0.1441} \\
\hline & & & & Transportation & & 0.2606 & \\
\hline & & & & Marketing & & 0.0843 & \\
\hline & & & & Launch Environment & & 0.1737 & \\
\hline \multirow{4}{*}{ Safety } & \multirow{4}{*}{ $\pm 20 \%$} & \multirow{4}{*}{0.2821} & & Population Density & \multirow{4}{*}{ $\pm 20 \%$} & 0.2344 & \multirow{4}{*}{0.0938} \\
\hline & & & & Flight Trajectory & & 0.4686 & \\
\hline & & & & Weather condition & & 0.0625 & \\
\hline & & & & Potential Disaster & & 0.2344 & \\
\hline
\end{tabular}

The expert evaluation method results are shown in Table 10. The results are consistent with the BWM and Ben-Tal method.

Table 10. The weights of the criteria evaluated with the expert evaluation method

\begin{tabular}{|c|c|c|c|}
\hline $\begin{array}{l}\text { Primary } \\
\text { criteria }\left(c_{n}\right)\end{array}$ & $\begin{array}{l}\text { Weights } \\
\left(w_{n}\right)\end{array}$ & Sub- criteria $\left(c_{n}\right)$ & $\begin{array}{l}\text { Weights } \\
\left(w_{n}\right)\end{array}$ \\
\hline \multirow{4}{*}{ Technical } & \multirow{4}{*}{0.50} & Launch Vehicle & 0.40 \\
\hline & & Orbit type & 0.25 \\
\hline & & Distance to Equator & 0.25 \\
\hline & & Launchpad & 0.10 \\
\hline \multirow{4}{*}{ Commercial } & \multirow{4}{*}{0.20} & Infrastructure & 0.45 \\
\hline & & Transportation & 0.25 \\
\hline & & Marketing & 0.10 \\
\hline & & Launch Environment & 0.20 \\
\hline \multirow{4}{*}{ Safety } & \multirow{4}{*}{0.30} & Population Density & 0.20 \\
\hline & & Flight Trajectory & 0.45 \\
\hline & & Weather condition & 0.10 \\
\hline & & Potential Disaster & 0.25 \\
\hline
\end{tabular}

The weights of the criteria obtained from the BWM are compared with the weights of the criteria obtained from the other two methods to verify the results. The differences between the values are shown in Figure 3. It is recognized that the differences are small; consequently, the best worst method results are consistent with the expert's evaluation method and the Ben-Tal method. 


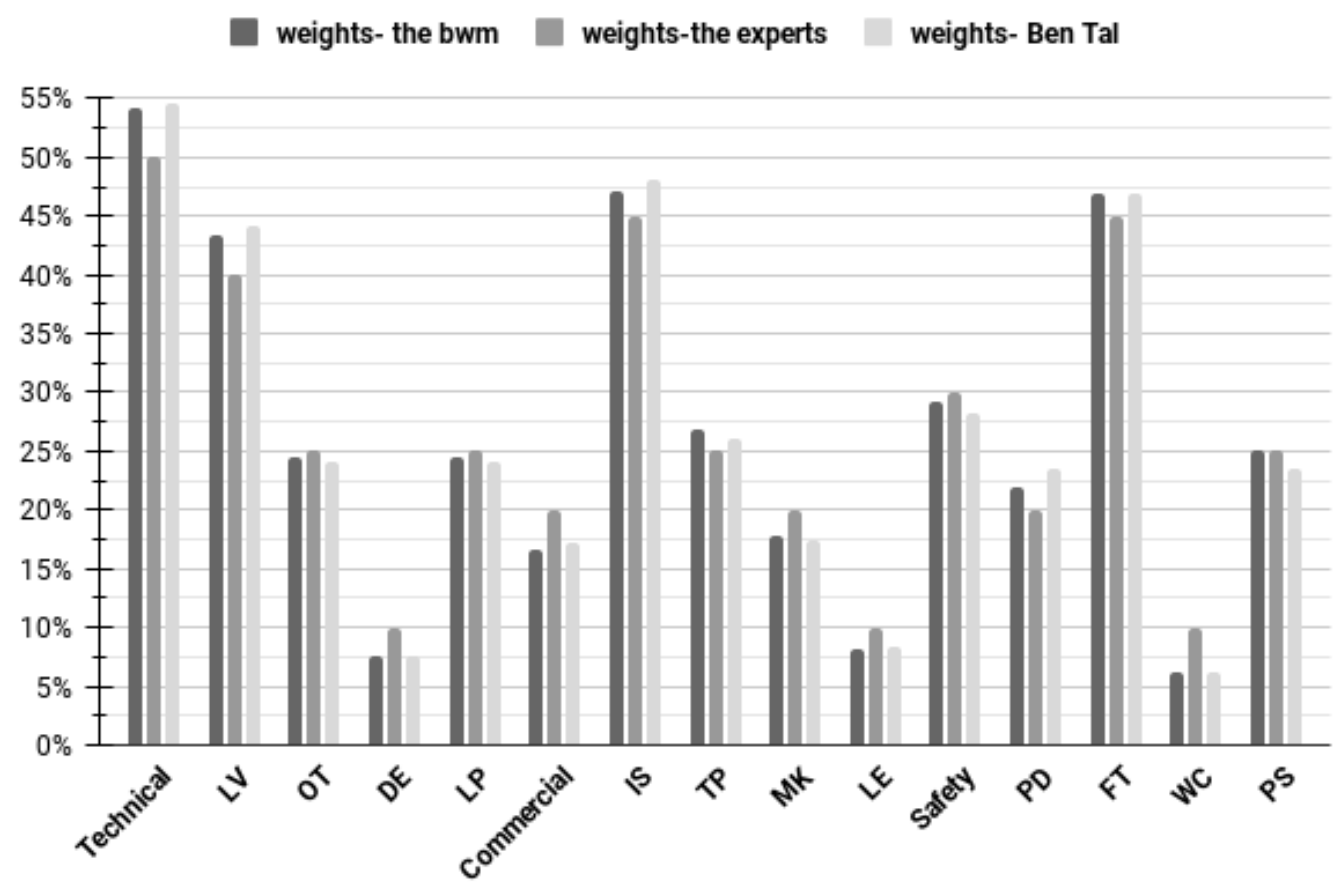

Figure 3. Comparison of all weights for 3 different methods; the BWM, the experts evaluation (intuitive) and Ben-Tal BWM including uncertainties

The points of sites (the decision-makers' scores) are the same in all evaluation methods. The final scores for ranking are obtained using the weighted sum method. The first group of site scores is obtained using the criteria obtained from the best-worst method and the scores in Table 3. Similarly, the second group of site scores for ranking is obtained using the weights of the criteria from and Ben-Tal's best and worst methods and data in Table 3. The third group of site scores for ranking is obtained from the experts who evaluated the weights of criteria and data in Table 3. Table 11 provides the final evaluated scores and each candidate location's ranking with the best worst method and uncertainties applied best and worst methods called Ben-Tal, and the experts' evaluation approach.

Table 11. Evaluated scores of the sites with the BWM, Ben-Tal BWM with applied uncertainty (error) and the expert evaluation

\begin{tabular}{llllllc}
\hline Location & The BWM & Ben-Tal & Expert Eval. & \multicolumn{2}{c}{ Ranking of } & 3 methods \\
\hline Sinop & $75.86 \%$ & $81.52 \%$ & $76.10 \%$ & 3 & 3 & 3 \\
Mugla & $74.84 \%$ & $80.16 \%$ & $74.88 \%$ & 4 & 4 & 4 \\
Cyprus & $80.70 \%$ & $84.55 \%$ & $80.48 \%$ & 2 & 2 & 2 \\
Somali & $91.25 \%$ & $90.71 \%$ & $90.08 \%$ & 1 & 1 & 1 \\
\hline
\end{tabular}

The results obtained with the best worst method indicate that the location's primary criteria weights are not close to each other. From technical criteria points of view, Somalia has the top score $(98.77 \%)$, while in commercial aspects, Sinop has the highest score (85.24\%). Safety scores of candidate sites have significant fluctuation, the worst is Kumluca, and the best location is again Somalia. Somalia has suggested the best launch site among four candidates. It is superior to other candidate sites regarding population density, orbital insertion physics, more convenient access to airspace, flight path safety (trajectory over Indian ocean), and lack of environmental constraints. Launch site located in a foreign state has the risk of damage to spaceport property and injury to third parties. In addition to that, an international agreement between Turkey and Somalia's governments must be considered. Somalia is a far apart location; consequently, transportation and security costs increase eventually. The secondary proposed launch site is Cyprus. It has a pleasant launch environment. It is geographically close to Turkey so transportation, and security costsaving possible compared to Somalia. Cyprus's disadvantage is a safe zone for flight trajectory; the safe 
flight path is short and about $250 \mathrm{~km}$. The third-ranked launch site is Sinop. Sinop is the worst location according to the distance to the equator criteria. Geosynchronous orbit mission has the advantages of launching payload at a site close to the equator. However, due to its launch environment safety reason, it gets third higher points, and the difference with Cyprus is very less.

Sinop has the top score in commercial aspects. Sinop is the best launch site among Turkey's provinces, according to this study. The fourth and last ranked launch site is Kumluca. The main driving point for Kumluca is the distance to equator criteria among Turkey's provinces. The commercial operation environment is enjoyable and pleasant. However, the safe zone for the flight path is minimal. The results show that the best worst method in the evaluation of weights of criteria provides reliable, acceptable, and practically usable solutions to support the administrator. The expert's evaluation and the Ben-Tal method, which has uncertainty, provide similar results, as shown in Table 11.

This study investigated the weights of the criteria in a site assessment by using the best- worst method. To our knowledge, it is the first study that demonstrates the best worst method in launch site selection. When we compare the method with other methods, the results indicate that the weights of the criteria are close to each other. Therefore, our results show that the weights of the technical criteria play an essential role in a site selection process.

\section{CONCLUSION}

The governments build their launch site to have independence in space flight missions and be members of entire space-faring nations. The geographical location of a launch site is strategic in various aspects. The selection of the right site location contributes to the success of the launch. The best-worst method was applied to evaluate the weights of the criteria and select a launch site in this study. The BWM results are consistent with other mentioned methods. It has been shown that the method produces consistent results to support the administrators. The proposed method is flexible, and by changing input parameters, this study can be extended for further space related works. This work assumes that a launch vehicle is single-use, expendable, and has a general rockets' performance. For the influence of a reusable launch vehicle or mighty powerful launch vehicle, as this change significantly affects the pairwise comparison matrix, new input parameters must be determined, and the results must be re-evaluated. As another alternative to input data, a launch site may be selected as a mobile maritime platform at sea and located at 0 -degree latitude for equatorial launch. The reasons for the equatorial launch are zero degrees of inclination, having more speed of earth rotation, reducing risks of launching over populated areas, and better safety. A mobile maritime platform located at the mediterranean sea may be a powerful solution for Turkey. Another method can be launching a payload to the first retrograde orbit, but it requires additional high delta velocity. Powerful launch vehicles can be developed to overcome some problems. The lunar and interplanetary missions launch site can also be assessed with this method. All those works require a change in input matrices and can be evaluated by the proposed method.

\section{CONFLICTS OF INTEREST}

No conflict of interest was declared by the author.

\section{REFERENCES}

[1] Ristono, A., Santoso, P. B., Tama, I. P. A., "Literature review of design of criteria for supplier selection”, Journal of Industrial Engineering and Management, 11, 4: 680- 696, (2018).

[2] Dachyar, M., Purnomo, H., "Spaceport site selection with analytical hierarchy process decision making", Indian Journal of Science and Technology, 11: 10, (2018). 
[3] Aksaker, N., Yerli, S. K., Erdoğan, M. A., Erdi, E., Kaba, K., Ak, T., Zati, A., Barış, V., Demircan, O., Evren, S., Keskin, V., Küçük, İ., Özdemir, T., Özışık, T., Selam, S., "Astronomical site selection for Turkey using GIS techniques", Experimental Astronomy, 39(3), 547-566, (2015).

[4] Finger, G., Keller, D., Gulliver, B., "Public-private spaceport development", SpaceOps 2008 Conference; Heidelberg, Germany, 3584, (2008).

[5] Erbuyuk, H., Ozcan, S., Karaboga, K., "Retail store location selection problem with multiple analytical hierarchy process of decision making an application in Turkey", Procedia-Social and Behavioral Sciences, 58: 1405-1414, (2012).

[6] Tugba, B., Tas, G., Herekoglu, A., Tozan, H., Vayvay, O., “A fuzzy AHP based decision support system for disaster center location selection and a case study for Istanbul", Disaster Prevention and Management, 20(5): 499-520, (2011).

[7] Koc-San, D., San, B., Bakis, V., Helvaci, M., Eker, Z., "Multi-criteria decision analysis integrated with GIS and remote sensing for astronomical observatory site selection in Antalya province, Turkey", Advances in Space Research, 52, 1: 39-51, (2013).

[8] Finger, G., David, K., Gulliver, B., "Launch site infrastructure cost trends", AIAA Space 2007 Conference and Exposition; Long Beach, CA, USA, 6014, (2007).

[9] Ahmad, W., Rezaei, J., Sadaghiani, S., Tavasszy, L., "Evaluation of the external forces affecting the sustainability of oil and gas supply chain using best worst method", Journal of Cleaner Production, 153: 242-252, (2017).

[10] Kumar, A., Sah, B., Singh, R., Deng, Y., He, X., Kumar, P., Bansal, R. C., "A review of multi criteria decision making (MCDM) towards sustainable renewable energy development", Renewable and Sustainable Energy Reviews, 69: 596-609, (2017).

[11] Chai, J., Liu, J. N. K., Ngai, E. W. T., "Application of decision-making techniques in supplier selection: A systematic review of literature", Expert Systems with Applications, 40(10): 38723885, (2013).

[12] Rezaei, J., "Best-worst multi-criteria decision-making method: some properties and a linear model", Omega, 64: 126-130, (2016).

[13] Pamučar, D., Ecer, F., Cirovic, G., Arlasheedi, M. A., "Application of improved Best Worst Method (BWM) in real-world problems", Mathematics, 8(8): 1342, (2020).

[14] Hasan, M., Gulzarul, Z., Mohammad, F., "Multi-choice best-worst multi-criteria decisionmaking method and its applications", International Journal of Intelligent Systems, (2021).

[15] Beemsterboer, D. J. C., Hendrix, E. M. T., Claassen, G. D. H., "On solving the best-worst method in multi-criteria decision-making", IFAC - Papers OnLine, 51(11): 1660-1665, (2018).

[16] Sadjadi, S., Karimi, M., "Best-worst multi-criteria decision-making method: A robust approach", Decision Science Letters, 7(4): 323-340, (2018). 